\title{
A arte no processo de desenvolvimento de pessoas portadoras do Transtorno do
}

\section{Espectro Autista (TEA)}

Art in the development process of people with Autistic Spectrum Disorders (ASD)

El arte en el proceso de desarrollo de personas con Trastornos del Espectro Autista (TEA)

Recebido: 17/06/2021 | Revisado: 22/06/2021 | Aceito: 25/06/2021 | Publicado: 10/07/2021

Igor Cardoso Costa

ORCID: https://orcid.org/0000-0002-8273-4598 Instituto Federal de Educação, Ciência e Tecnologia de Minas Gerais, Brasil E-mail: igorcardoso15@gmail.com

Jeanne Vieira Soares

ORCID: https://orcid.org/0000-0002-3924-4307 Instituto Federal de Educação, Ciência e Tecnologia de Minas Gerais, Brasil E-mail: geannehistoria@gmail.com

Paulo Henrique Araújo

ORCID: https://orcid.org/0000-0002-0804-7933 Instituto Federal de Educação, Ciência e Tecnologia de Minas Gerais, Brasil E-mail: paulo.araujo@ifmg.edu.br

\begin{abstract}
Resumo
A sala de aula é constituída pela diversidade, nela nos deparamos com alunos de diferentes classes sociais e diversas necessidades educacionais especiais dentre as quais encontra-se o Transtorno do Espectro Autista (TEA). O contato com esse segmento de estudantes tem exigido dos profissionais da educação, sobretudo dos professores de arte, a necessidade de aprimorar suas práticas educativas e pedagógicas afim de compreender as especificidades que cada aluno apresenta no processo de ensino/aprendizagem. O objetivo deste estudo é o de analisar como ensino de arte influência no processo de socialização e aprendizagem de alunos autistas. Para atingir o objetivo a metodologia empregada caracteriza-se como sendo de revisão bibliográfica, para tanto o estudo foi dividido em três partes: primeiramente fazse uma menção às características e diagnósticos do Transtorno do Espectro Autista, no segundo momento, seguiremos com levantamento das leis que regulamentam a educação inclusiva no país, por fim, investigaremos se a arte nas áreas de música, teatro e dança contribuem para o desenvolvimento dos indivíduos com TEA. Constatou que o autismo caracteriza pela ausência de interesse em manter relações interpessoais, dificuldades na linguagem e na comunicação e interesses peculiares por determinados objetos e comportamentos estereotipados, nesse sentido concluiu que atividades lúdicas que envolva a dança, a música e o teatro proporcionam uma melhora considerável no aspecto cognitivo, psicomotor como também no aspecto emocional e nas relações afetivas.
\end{abstract}

Palavra-chave: Autismo; Educação inclusiva; Ensino de artes; Ensino.

\begin{abstract}
The classroom is constituted by diversity, in it we come across students from different social classes and different special educational needs, among which is the Autistic Spectrum Disorder (ASD). Contact with this segment of students has demanded from education professionals, especially art teachers, the need to improve their educational and pedagogical practices in order to understand the specificities that each student has in the teaching/learning process. The aim of this study is to analyze how art teaching influences the socialization and learning process of autistic students. To achieve the objective, the methodology used is characterized as being a literature review, for this the study was divided into three parts: firstly, there is a mention of the characteristics and diagnoses of the Autistic Spectrum Disorder, in the second moment, we will continue with a survey of the laws that regulate inclusive education in the country, finally, we will investigate whether art in the areas of music, theater and dance contribute to the development of individuals with ASD. It found that autism is characterized by the lack of interest in maintaining interpersonal relationships, difficulties in language and communication and peculiar interests in certain objects and stereotyped behaviors, in this sense concluded that recreational activities involving dance, music and theater provide a considerable improvement in the cognitive, psychomotor aspect as well as in the emotional aspect and in affective relationships.
\end{abstract}

Keyword: Autism; Inclusive education; Arts education; Teaching.

\section{Resumen}

El aula está constituida por la diversidad, en ella nos encontramos con alumnos de diferentes clases sociales y diferentes necesidades educativas especiales, entre las que se encuentra el Trastorno del Espectro Autista (TEA). El contacto con este segmento de estudiantes ha exigido a los profesionales de la educación, especialmente a los profesores de arte, la 
necesidad de mejorar sus prácticas educativas y pedagógicas para comprender las especificidades que tiene cada estudiante en el proceso de enseñanza / aprendizaje. El objetivo de este estudio es analizar cómo la enseñanza del arte influye en el proceso de socialización y aprendizaje de los estudiantes autistas. Para lograr el objetivo, la metodología utilizada se caracteriza por ser una revisión de la literatura, para ello el estudio se dividió en tres partes: en primer lugar, se hace mención a las características y diagnósticos del Trastorno del Espectro Autista. Las leyes que regulan la educación inclusiva en el país, finalmente, investigaremos si el arte en las áreas de música, teatro y danza contribuye al desarrollo de las personas con TEA. Encontró que el autismo se caracteriza por la falta de interés en mantener relaciones interpersonales, dificultades en el lenguaje y la comunicación e intereses peculiares en ciertos objetos y conductas estereotipadas, en este sentido concluyó que las actividades recreativas que involucran danza, música y teatro brindan una mejora considerable en el aspecto cognitivo, psicomotor, así como en el aspecto emocional y en las relaciones afectivas.

Palabra clave: Autismo; Educación inclusiva; Educación artística; Enseñanza.

\section{Introdução}

A arte é uma das primeiras manifestações utilizadas pela humanidade como forma de marcar presença, seja criando objetos ou formas que representam sua vivência no mundo, comunicando e expressando ideias e sentimentos, através de pinturas nas cavernas, roupas, filmes, templos religiosos, quadros, etc., o que demonstra a importância desse saber para o ser humano. Por esse motivo, a aprendizagem de Arte precisa alcançar a experiência e a vivência artísticas como prática social, permitindo que os alunos, com necessidades especiais ou não, sejam protagonistas e desenvolvam seu potencial, expressando suas emoções, sensações e percepções.

A sala de aula é constituída pela diversidade, nela nos deparamos com alunos de diferentes classes sociais, etnias e culturas, e com diversas necessidades educacionais especiais tais como: visuais, de altas habilidades/superdotação e de transtornos globais de desenvolvimento, entre estes, o Transtorno do Espectro Autista (TEA). O contato com este último segmento de estudantes vem exigindo dos docentes, sobretudo dos professores de arte, a necessidade de aprimorar suas práticas educativas e pedagógicas, visando compreender as especificidades que cada aluno apresenta no processo de socialização e aprendizagem.

Acredita-se que o professor, através das atividades artísticas, pode proporcionar aos indivíduos com TEA experiências que irão contribuir com o desenvolvimento da comunicação, o domínio motor e a maior interação com os colegas e docentes. Assim, motivados a realizar esta discussão, elencamos um problema que norteou este estudo: como o ensino de arte contribui com desenvolvimento do aluno com Transtorno do Espectro Autista?

A relevância desta discussão parte da premissa de que uma escola inclusiva está voltada para a cidadania global, plena, livre de preconceitos e que reconhece e valoriza as diferenças, sendo assim, é necessário que a Escola entenda a diversidade dos seus alunos e organize as práticas educacionais de maneira a incluir todos e atender as particularidades de cada um (Mantoan, 2003). É neste momento que apresenta-se um desafio, isto porque, embora a igualdade de condições para acesso e permanência na escola esteja assegurado pela Constituição Federal em seu Art.206, dados do Índice de Desenvolvimento da Educação Básica IDEB (2019) apontam que a proporção de alunos que aprenderam o adequado na competência de leitura e interpretação de textos na rede pública de ensino foi de 57\%, esse índice pode ser ainda menor em se tratando de alunos com Transtorno do Espectro Autista, tendo e vista que estes apresentam muitas dificuldades no processo de ensino-aprendizagem devido à especificidade comportamental do TEA. Os alunos com necessidades educacionais especiais ficam a maior parte do tempo sem participar das atividades, apenas observando como se não fizessem parte do ambiente, tornando-se irritados, agressivos e se negando a permanecer na sala de aula.

A prática inclusiva é um processo contínuo e coletivo, todos têm o direito de participar e de aprender, daí a necessidade de estratégias diversificadas e adequadas para se trabalhar com um grupo heterogêneo. Nesse sentido, a arte pode ser uma ferramenta valiosa no processo de ensino-aprendizagem de crianças autistas, porque é um elemento fundamental para desenvolver atividades que configurem um estímulo para sua inserção social e desenvolvimento da comunicação. 
O estudo foi dividido em três partes: primeiramente faz-se uma menção às características e diagnósticos do Transtorno do Espectro Autista, no segundo momento, seguiremos com levantamento das leis que regulamentam a educação inclusiva no país, por fim, investigaremos se a arte nas áreas de música, teatro e dança contribuem para promover a inclusão de alunos com TEA.

\section{Metodologia}

Na realização do estudo, aplicou-se a revisão bibliográfica exploratória como metodologia, segundo Matos (2015), esse método tem como finalidade levantar todas as referências encontradas sobre determinado tema. Para tanto foi utilizado artigos acessados nas bases de dados Scielo, Capes e em livros; sendo 15 artigos nacionais e 1 internacional, todos disponíveis online em texto completo e publicados no período de 2002 a 2021. Além dos artigos 4 livros com os descritores educação inclusiva, características e diagnostico autista forma utilizados.

Para critério de seleção das bibliografias, empregou-se as seguintes palavras chaves: Transtorno do Expecto Autista, educação inclusiva e Ensino de artes. Em sequência foram excluídos aquelas que não atenderam a temática ou que foram publicados a muito tempo. Após a coleta de dados uma foi feita uma leitura rápida apenas dos resumos com intenção de verificar se a obra era relevante para a pesquisa, aqueles selecionados passaram por uma leitura minuciosa e analítica, visando extrair informações que respondesse o problema da pesquisa.

\section{Desenvolvimento}

\subsection{Características do Transtorno do Espectro Autista (TEA)}

Até a década de 1930, não havia conceituação por parte da psiquiatria para o que mais tarde veio a ser denominado como autismo. Segundo Gómez (2014), as características do autismo são ausência de interesse em manter relações interpessoais, dificuldades na linguagem e na comunicação e interesses peculiares por determinados objetos e comportamentos estereotipados. Em 1943, passou-se a utilizar o termo autismo para diagnosticar o transtorno do espectro autista (TEA):

O transtorno do espectro autista (TEA) é um grupo de distúrbios do desenvolvimento neurológico de início precoce, caracterizado por comprometimento das habilidades sociais e de comunicação, além de comportamentos estereotipados. Embora definido por estes principais sintomas, o fenótipo dos pacientes com TEA pode variar muito, abrangendo desde indivíduos com deficiência intelectual (DI) grave e baixo desempenho em habilidades comportamentais adaptativas, até indivíduos com quociente de inteligência (QI) normal, que levam uma vida independente. Estes indivíduos também podem apresentar uma série de outras comorbidades, como hiperatividade, distúrbios de sono e gastrintestinais, e epilepsia (Oliveira et al., 2017).

Acredita-se que haja determinados fatores, como uso de alguns medicamentos durante o período gestacional, infecções e interferências ambientais, que possam contribuir para que o indivíduo nasça com TEA. Entretanto, os fatores genéticos são responsáveis por cerca de $50 \%$ a $90 \%$ dos casos.

O Transtorno do Espectro Autista, por impactar o desenvolvimento humano de diversas maneiras, cria a necessidade de que haja uma atenção maior para esses alunos por parte dos profissionais da educação. Nesse sentido Garcia et,al (2020) frisa as peculiaridades entre os autistas, não apenas no modo como o autismo se expressa, mas também na subjacência de seus temperamentos, personalidades e competências; de acordo com os autores existem níveis graves de autismo com autoagressão e forte resistência a mudanças, assim como, há indivíduos autistas com nível de inteligência altíssimo considerados, verdadeiros talentos musicais, excelentes dançarinos, com habilidades de memorização, desenhos e pinturas. E exatamente essas particularidades do autismo é o que dificulta na hora de traçar um perfil exclusivo e único do TEA, daí a importância de os pais ficarem atentos ao desenvolvimento da criança nos primeiros meses de vida. 
Em 2012, a presidenta Dilma Rousseff sancionou a Lei no 12.764, conhecida como lei do autismo, que trouxe inúmeros avanços quanto aos direitos da pessoa que possui TEA, em especial ao acesso educacional do sistema público, destacado no Art. $2^{\text {o: }}$

(...) São direitos da pessoa com autismo:

$\S$ IV. O acesso: A educação e o ensino profissionalizante

(...) Parágrafo Único: em casos de comprovada necessidade, a pessoa com Transtorno do Espectro Autista incluída nas classes comuns de ensino regular, nos termos do Inciso IV do Art. $2^{\circ}$; terá direito a acompanhante especializado. (BRASIL, 2010).

Vale ressaltar que, somando-se a esta, há outras diretrizes que regulamentam quanto aos requisitos necessários para atender as necessidades de alunos especiais junto ao ensino regular, todas, resultado do histórico de lutas por direitos tanto em âmbito nacional, quanto internacional. Entretanto, é valido ressaltar a importância do diagnóstico precoce dos alunos com TEA, para que assim eles tenham seus direitos preservados.

\subsection{Diagnóstico}

Atualmente o diagnostico de pessoas com o Transtorno do Espectro Autista (TEA) se dá de maneira mais rápida que no passado e é um diagnóstico essencialmente clínico. Segundo Araújo e Saraiva (2015), o TEA origina-se nos primeiros anos de vida, entretanto não é uniforme, variando de caso a caso. Há relatos de que os sintomas se apresentam nos primeiros meses após o nascimento, mas que, em sua maioria, são identificados de forma consistente entre 1 a 2 anos de vida.

Para o diagnóstico, há vários métodos a serem adotados, o mais comum é observar as formas de comunicação verbal e não verbal, sendo que na comunicação verbal tem-se observado que o indivíduo com TEA possui alteração na forma da emissão de sons (prosódia), além de apresentar desvios semânticos. Ainda sobre o diagnóstico, são observadas suas interações sociais e a conduta sobre a afinidade com determinadas atividades.

Yoshijinna (2000) descreve algumas características que permitem reconhecer pessoas com autismo; elas podem se manifestar em diferentes níveis e variar a cada caso:

- Isolamento mental, podendo ser caracterizado pela exclusão, desprezo ou ignorância do que vem do externo;

- Insistência que beira à obsessão na repetição;

- Obediência a rotinas e rituais no dia a dia;

- Fascinação e fixação intensa direcionada a algo específico;

- Escassas expressões faciais e gestos, além de não olhar diretamente para outras pessoas;

- Utilização anormal da linguagem;

- Bom relacionamento com objetos;

- Ansiedade excessiva;

- Ausência da fala ou ainda perda da fala anteriormente adquirida.

Segundo a Associação Americana de Psiquiatria (2014) é valido ressaltar que os sintomas podem ser divididos em três graus, sendo eles:

- Baixo: a linguagem não é funcional e o indivíduo tende a se isolar socialmente.

- Médio: nesse grau o indivíduo pode aceitar a interação social, mas não a procura, também pode haver algum grau de linguagem espontânea.

- Alto: é observado em pessoas um pouco mais velhas, podem ter interesse nas interações, entretanto possuem dificuldade em iniciá-las e mantê-las. Nesse grau estão inclusas as pessoas com a Síndrome de Asperger, que é uma variação do TEA. 
Visto que o indivíduo com TEA apresenta algumas limitações, fica evidente que no ambiente escolar ele necessita de um apoio especializado. Na legislação brasileira esses alunos são incluídos na educação inclusiva, portanto, a seguir, faz-se um recorte sobre a legislação que os contempla.

\subsection{Leis da educação inclusiva}

O documento Marco Político Legal da Educação Especial na Perspectiva da Educação Inclusiva, de 2010, fornece-nos um histórico da atenção educacional dada às pessoas com deficiências no Brasil.

A Educação especial se inicia ainda no Brasil Império, com a criação de duas instituições que visavam ensinar pessoas com necessidades especiais: o Imperial Instituto dos Meninos Cegos, em 1854, atualmente conhecido como Instituto Benjamin Constant (IBC), e posteriormente, em 1857, o Instituto Nacional da Educação de Surdos (INES), ambos se localizam no Rio de Janeiro. No início do século XX, foi fundado o Instituto Pestalozzi (1926), instituição especializada no atendimento às pessoas com deficiência mental; em 1954, a primeira Associação de Pais e Amigos dos Excepcionais (APAE); e, em 1945, foi criado o primeiro atendimento educacional especializado às pessoas com superdotação na Sociedade Pestalozzi, por Helena Antipoff (Mazzotta, 1999).

Na década de 90, documentos como a Declaração Mundial de Educação para Todos (1990) e a Declaração de Salamanca ${ }^{i}$ (1994) passam a exercer influência na formulação das políticas públicas da educação inclusiva.

Nós congregamos todos os governos e demandamos que eles: atribuam a mais alta prioridade política e financeira ao aprimoramento de seus sistemas educacionais no sentido de se tornarem aptos a incluírem todas as crianças, independentemente de suas diferenças ou dificuldades individuais; adotem o princípio de educação inclusiva em forma de lei ou de política, matriculando todas as crianças em escolas regulares, a menos que existam fortes razões para agir de outra forma; desenvolvam projetos de demonstração e encorajem intercâmbios em países que possuam experiências de escolarização inclusiva; estabeleçam mecanismos participatórios e descentralizados para planejamento, revisão e avaliação de provisão educacional para crianças e adultos com necessidades educacionais especiais (SALAMANCA, 1994).

O Plano Nacional de Educação (PNE) ${ }^{\mathrm{ii}}$, Lei n ${ }^{\circ}$ 10.172/2001, destaca avanços significativos e demonstra que a construção de uma escola inclusiva que possa garantir o atendimento à diversidade do ser humano seria um dos maiores sucessos que se poderia obter. Com as novas metas e objetivos do PNE, fica evidenciado que há um déficit de oferta de matrículas para alunos com deficiência.

Em 1999 foi promulgada no Brasil o Decreto n 3.956/2001, afirmando que:

As pessoas com deficiência têm os mesmos direitos humanos e liberdades fundamentais que as demais pessoas, definindo como discriminação com base na deficiência toda diferenciação ou exclusão que possa impedir ou anular o exercício dos direitos humanos e de suas liberdades fundamentais.

O Decreto 3.956/2001 teve uma importante repercussão na educação, exigindo que houvesse uma reinterpretação do termo "educação especial", com o intuito de retirar as barreiras que impediam o acesso à escolarização.

Um outro ponto que necessitou ser debatido foi a formação docente; em 2007, foi lançado o Plano de Desenvolvimento da Educação - PDE, tendo como eixos:

\footnotetext{
' Declaração de Salamanca, trata-se de um documento elaborado na Conferência Mundial sobre a Educação especial, realizado em 1994 na cidade de Salamanca na Espanha. O documento objetivou fornece diretrizes para a reformulação de políticas e do sistema educacional para que houvesse a inclusão e assim o Estado assegurar a educação de pessoas com deficiências

ii Plano Nacional de Educação (PNE), é a lei que estabelece as metas e diretrizes visando o desenvolvimento nacional, estadual e municipal da educação.
} 
A formação de professores para a educação especial, a implantação de salas de recursos multifuncionais, a acessibilidade arquitetônica dos prédios escolares, acesso e a permanência das pessoas com deficiência na educação superior e o monitoramento do acesso à escola dos favorecidos pelo Benefício de Prestação Continuada - BPC (PDE, 2017).

Para a efetivação do PDE é publicado o Decreto $n^{\circ}$ 6.094/2007, que determina nas diretrizes do Compromisso Todos pela Educação, “a garantia do acesso e permanência no ensino regular e o atendimento às necessidades educacionais especiais dos alunos, fortalecendo seu ingresso nas escolas públicas”.

O Projeto de Lei que estabelece o Plano Nacional de Educação PNE(2011/2020) define no artigo $8^{\circ}$, $2^{\circ}$ que os entes federados deverão estabelecer em seus planos de educação metas para garantir o pleno acesso à educação regular e a oferta do atendimento educacional especializado complementar à formação dos estudantes público-alvo da educação especial. A meta 4 do mesmo prevê:

Universalizar, para a população de 4 a 17 anos, o atendimento escolar aos estudantes com deficiência, transtornos globais do desenvolvimento e altas habilidades ou superdotação na rede regular de ensino. Dentre as estratégias, está garantir repasses duplos do Fundo de Manutenção e Desenvolvimento da Educação Básica e de Valorização dos Profissionais da Educação (FUNDEB) a estudantes incluídos; implantar mais salas de recursos multifuncionais; fomentar a formação de professores de AEE; ampliar a oferta do AEE; manter e aprofundar o programa nacional de acessibilidade nas escolas públicas; promover a articulação entre o ensino regular e o AEE; acompanhar e monitorar o acesso à escola de quem recebe o benefício de prestação continuada (Abreu et al., 2011).

Embora o aluno com transtorno do espectro autista esteja contemplado nas normativas da educação inclusiva, a lei 12.764/2012 também conhecida como Lei Berenice Piana institui a Política Nacional de Proteção dos Direitos da Pessoa com Transtorno do Espectro Autista, que é a primeira lei direcionada especificamente para esses indivíduos e nela o portador de TEA é considerado como pessoa deficiente.

\section{Resultados e Discussão}

\subsection{Arte e a inclusão de alunos com TEA}

É importante aqui fazermos um breve relato de como se iniciou o uso da arte nos tratamentos psiquiátricos.

Entre o fim do século XIX e o início do século XX, nos ambientes destinados a cuidados psiquiátricos, foram introduzidas as atividades artísticas, o que ficou conhecido como arteterapia cientifica surge no século XX, seguida pela musicoterapia. Segundo Forestier (2011), a verdadeira arteterapia só é conhecida na década de 1960, vista como o total domínio que está relacionado a todo conjunto das técnicas artísticas empregadas no tratamento de pessoas com algum tipo de deficiência mental ou de aprendizagem.

Segundo Tommasi (2015), a arteterapia contribui para estimular a imaginação as emoções efetivas, ainda segunda a autora a arteterapia tem várias ramificações, e tem sustentação na arte e na psicologia.

No Brasil, Nise da Silveira foi pioneira na introdução da arteterapia nos centros de cuidados psiquiátricos; a médica manifestava-se contra o uso de choques e da lobotomia no tratamento psiquiátrico, por isso, observou a necessidade de criar dentro do Centro Psiquiátrico Nacional uma ala onde iniciou o tratamento psiquiátrico através da arte. (Castro; Lima, 2007).

O uso da arte em tratamentos psiquiátricos foi popularizado país afora a fim de propiciar melhores condições de vida e no desenvolvimento dos pacientes que dela necessita para seu tratamento psiquiátrico. A seguir veremos como a formação docente tem impacto na vida dos alunos com TEA.

Os professores enfrentam grandes dificuldades para promover a inclusão de alunos com TEA, isso se dá porque grande parte utiliza os procedimentos pedagógicos que aprenderam na época de sua formação, que podem ser pouco úteis no contexto educacional atual. Borges (2015) afirma que a solução pode estar em metodologias centradas na percepção do mundo natural, 
com ações pedagógicas que enfoquem as diferenças.

Ao entrar em uma sala onde se encontram reunidos alunos com TEA, inicialmente o choque provocado pelo isolamento em que eles se encontram é muito grande. $\mathrm{O}$ desafio que se apresenta é encontrar alternativas que possam favorecer de alguma maneira a comunicação para a inserção desses indivíduos em seu meio (Borges, 2015).

Diante do exposto Carvalho et al., (2019) ressalta que, para obtenção de um bom resultado no processo de ensinoaprendizagem de alunos com TEA, o professor deve ter propriedade nas práticas aplicadas e conhecimento pleno do que é o autismo, segundo os autores é importante que os profissionais se aproprie de estratégicas pedagógicas que respeite a individualidade e as peculiaridades de cada aluno, utilizando e propondo metodologias cada vez mais eficazes no intuito de despertar o interesse dos alunos e facilitar o processo de aprendizagem.

Várias estratégias são experimentadas, alguns avanços são obtidos e outros nem tanto, é um processo de ir e vir, fazer acontecer. Uma alternativa que tem sido empregada em sala de aula é o uso da arte, visto que ela contribui para que o indivíduo com TEA compreenda as imagens ao redor e dê sentido a elas; essa apropriação é primordial para o desenvolvimento cognitivo do aluno com transtorno do espectro autista.

Conforme, a arte constitui-se como umas das possibilidades para a aquisição das habilidades de expressão verbal e não verbal, pois possibilita o interagir entre esses indivíduos e o mundo exterior, facilitando assim a comunicação e o fazer espontâneo, despertando o imaginário da criança autista (Maciel, 2019).

A arte terapia que nada mais é que a junção da arte e da psicologia é um dos métodos aplicados no processo de aperfeiçoamento das habilidades dos indivíduos com TEA.

Vygotsky (1999) enfatiza que o imaginário é o alicerce de toda a atividade criadora e manifesta-se em todos os aspectos da vida cultural, possibilitando a criação artística, científica e técnica. Ainda segundo o autor, o ser humano desenvolve sua criatividade através de sua imaginação desde a infância e, por isso, as atividades que estimulam a criação desde os dois anos são importantes para o desenvolvimento como um todo. Todavia, o comportamento do autista tende a se tornar uma barreira que dificulta o acesso à ludicidade.

A educação e a arte têm seu poder de alagar a imaginação e refinar os sentidos, promovendo mudanças significativas nos olhares em direção a novas percepções sobre o mundo. Nesse contexto, o que se observa é que a arte, enquanto ferramenta pedagógica, favorece os alunos com TEA, visto que ajuda a expor seus sentimentos de forma concreta. Nesse sentido Dias et al, (2020) corrobora enfatizando que na arte-educação aprende-se a partir das experiências, considerando-se a história de vida dos discentes, suas subjetividades e emoções, indo de encontro da autonomia, promovendo práticas de ensino-aprendizagem que compreendem o ser humano de forma integral.

Para Maciel (2019), o ensino de arte propicia as crianças com o transtorno do espectro autista, materiais lúdicos que colaboram para que eles possam fazer experimentações e descobertas, e isso contribui para que haja a construção de eles socioemocionais, além de contribuir com o desenvolvimento fatores referentes aos aspectos sensório-motor.

Fernandes et al., (2011), em sua pesquisa de campo, cujo objetivo foi investigar vivências sensoriais em atividades artísticas que possam ser estimulantes para os alunos com TEA, constatou, ao observar a conduta desse público frente as atividades lúdicas, como recortes, pinturas, texturas, modelagem e música clássica, uma melhora considerável em metade dos alunos envolvidos. Segundo a autora, tal melhora ocorreu tanto nas operacionalizações das atividades, no aspecto cognitivo e psicomotor, como também no aspecto emocional e nas relações afetivas destes alunos com os orientadores das oficinas.

As formas, as cores, as texturas dos materiais apresentados aos alunos com TEA, despertam curiosidades. Alguns são capazes de passar vários minutos observando determinada cor e seus olhares indicam certa alegria, um contentamento que só se explica pela presença desses estímulos, e esses estímulos são importantes para o seu desenvolvimento 
(Fernandes et al., 2011).

A arte propicia à criança uma ressignificação do mundo, ao tocar materiais e explorá-los espontaneamente, ela consegue criar suas produções individuais. Nos alunos com autismo, essas descobertas são livres, pois não se espera um resultado, apenas se experimenta. E são essas experimentações que fazem com que o aluno se desenvolva, adquirindo novas habilidades e competências, superando as dificuldades características do transtorno. A seguir, veremos como a dança, o teatro e a música podem contribuir para o desenvolvimento dos indivíduos com TEA.

\subsection{Dança}

A dança se destaca como uma linguagem corporal e é usada como ferramenta para propiciar desenvolvimento a indivíduos com alguma forma de limitação. Para pessoas autistas, a dança traz a possibilidade de desenvolver o processo criativo e a socialização entre os indivíduos. Ela também pode contribuir para a construção do sentimento de valorização e aceitação, contribuindo para evitar o desenvolvimento de sentimentos de inferioridade.

Pessoas com autismo tendem a apresentar déficits na comunicação e interação social, junto a padrões restritos e repetitivos de comportamento, interesses ou atividades. O manual da American Psychiatric Association (2013) diz que a dança pode ser utilizada como uma estratégia estimuladora no desenvolvimento de pessoas com autismo.

Na mesma linha da Associação Americana de Psiquiatria, Machado (2015) nos diz que:

A dança como terapia pode estimular a integração da sensação, da percepção e, assim, predispor a ação. Atividades coordenadas são de fundamental importância para o progresso do aparato neuromotor. A terapia motora associada à música pode facilitar a interação social e a comunicação, além de vários sistemas que interferem na percepção do movimento, fundamentais para o desenvolvimento emocional-social e para a interconexão de áreas responsáveis pela associação do movimento.

Teixeira Machado (2015) associou que a dança contribuiu para o desenvolvimento da expressão motora e gestual dos indivíduos autistas que participaram da sua pesquisa, trazendo melhora significativa na qualidade de vida.

No âmbito educacional a dança proporciona ao aluno com TEA um maior contato dele com os demais colegas. Vargas (2005) em seu estudo aponta que a utilização da dança no ambiente pedagógico gerou muitos frutos, como: alteração da autoestima, interação dos alunos e um melhor comportamento de alunos considerados indisciplinados. Nesse contexto Boato (2013 e 2014), nos diz que a adoção da dança no tratamento de autistas propiciou mudanças no comportamento socioemocional.

No estudo desenvolvido por Aleixo e Ruiz (2008) onde eles observaram o desenvolvimento de uma aluna de 21 anos com a Síndrome de Asperger, que é um Transtorno do Espectro Autista, após a inclusão da dança nas atividades pedagógicas pôde-se observar:

Evolução na sociabilização, na relação interpessoal, no comportamento lúdico, na expressão corporal, na fala, no relacionamento com o grupo de dança, com a família e com a sociedade. Estabelecendo, assim, um melhor contato visual, sendo notado interesse pelas aulas e o início da participação em apresentações sociais (ALEIXO E RUIZ, 2008).

A inserção da dança no processo de desenvolvimento dos indivíduos com TEA tem apresentado resultados satisfatórios, tanto no desenvolvimento motor quanto no processo de interação social, todo esse desenvolvimento é fundamental pois contribui para que esse indivíduo possa ser incluso na sociedade. 


\subsection{Teatro}

O teatro é uma das formas onde o ser humano pode representar suas alegrias, angústias, tristezas e os demais sentimentos. Sua função pedagógica, segundo Arcoverde (2008). é "mostrar o comportamento social e moral, através do aprendizado de valores e no bom relacionamento com as pessoas". Para os alunos com TEA é um modo de desenvolver essas expressões.

A seguir, veremos um trecho do relato de Pérola (2018), que é autista é ex-aluno do curso de Teatro da Universidade Federal de Pelotas.

"O teatro é Alívio Imediato, pois, entre outras coisas, me dá a permissão para ser ou parecer ser quem eu não sou. Não que eu não goste de ser quem eu sou, mas ser sempre o mesmo às vezes enjoa. No teatro posso experimentar várias e diferentes formas de $\operatorname{ser}(. .$.

(...) Mas, retomando a questão do teatro, dessa vez o teatro-cena: mantendo essa mesma linha reflexiva, chego à possível conclusão de que só consigo fazer o que faço no teatro porquê de alguma forma aprendi a não duvidar de que o que faço é o certo e que eu posso fazê-lo. Ou seja, a Síndrome de Asperger trouxe-me dificuldades de comunicação durante a infância e adolescência e, a partir daí me acostumei a ser, fora do teatro, um ser silencioso. Ao mesmo tempo, as poucas experiências que tive assistindo teatro nessa mesma época me ensinaram que no teatro há falas e que essas falas não são minhas, mas sim dos personagens que represento (...)" (Pérola, 2018).

Pérola possui a síndrome de Asperger e ele relata como é benéfico o teatro em sua vida e como o ajuda em seu desenvolvimento pessoal. É importante salientar que Pérola mesmo com todas as limitações, teve acesso ao ensino superior, o que contribui para o seu desenvolvimento pessoal. É importante que outras pessoas com TEA tenham a oportunidade de experimentar novas sensações que contribuam de forma efetiva na estimulação sensorial e cognitiva.

\subsection{Música}

A música é uma forma de arte que está presente em todas as culturas conhecidas, ela é utilizada desde o entretenimento até às terapias. Araújo (2015) destaca que a música pode ser aplicada na prática pedagógica, pois com ela é possível construir pontes entre o aluno e o professor.

$\mathrm{Na}$ Educação Infantil a música oferece inúmeros benefícios para o aluno, para o professor e para a interação em sala de aula.

O processo de aquisição da educação musical também facilita a comparação com a expressão musical: da fase de exploração vocal à etapa de reprodução, criação e reconhecimento das primeiras letras, daí à grafia de palavras, depois as frases e, enfim, à leitura e a escrita, existe um caminho que envolve a permanente reorganização de percepções, explorações, descobertas, construções de hipóteses, reflexões e sentidos que tornam significativas todas as transformações e conquistas de conhecimentos: a consciência em contínuo movimento. Isso ocorre também com a música (BRITO, 2003).

No processo de acompanhamento de indivíduos com TEA, costuma-se usar a musicoterapia. Gfeller (2008) afirma que a música é utilizada para além do entretenimento, mas também para acalmar crianças agitadas, ensinar emoções, desenvolver a consciência social, entre outros.

A World Federation of Music Therapy (2011) afirma que:

Musicoterapia é o uso profissional da música e de seus elementos como uma intervenção em ambientes médicos, educacionais e cotidianos com indivíduos, grupos, famílias ou comunidades que busca otimizar sua qualidade de vida e melhorar sua saúde e bem-estar físico, social, comunicacional, emocional, intelectual e espiritual. 
A músico terapia tem se mostrado como uma grande aliada para o tratamento de pessoas com TEA, pois além de contribui com o desenvolvimento cognitivo também ajuda o indivíduo no desenvolvimento e a aquisição da linguagem verbal e não verbal.

Percebe-se que a experiência sonora e musical são fatores extremamente importantes e eficazes na facilitação do desenvolvimento linguístico tanto verbal quanto não verbal para pessoas diagnosticadas com Transtorno do Espectro do Autista. A música é um instrumento muito importante na comunicação não verbal, através dela é possível exprimir sentimentos, notou-se também que a musicoterapia faz com que a criança diagnostica com TEA (Transtorno do Espectro do Autista) se desenvolva, consiga se comunicar através de gestos, fique menos estressada, mais calma, menos agitada, além de socializar com mais facilidade (Sampaio et al., 2017).

No estudo de Freire e Parizzi (2015), é relatado que foi introduzido na rotina de um aluno de 04 anos sessões de musicoterapia, durante um período de 04 meses, a seguir veremos um breve relato desta experiência:

As primeiras sessões foram marcadas por seus movimentos estereotipados rodando o tambor de aro(...)

$\mathrm{Na}$ quarta sessão, o paciente demonstrou maior intenção em explorar os sons, começando a se engajar no fazer musical conjunto. Isso pôde ser percebido no momento em que as batidas fortes e compulsivas feitas por ele no tambor tornouse a marcação do pulso(...)

Nas sessões seguintes, com o engajamento no fazer musical conjunto, podemos notar o desenvolvimento musical do indivíduo, acompanhado do fortalecimento do vínculo terapêutico e da expansão de sua expressividade. Esses crescimentos, pouco a pouco vão propiciando o desenvolvimento integral da criança, visível principalmente, no desenvolvimento da fala, na melhora da qualidade das interações e no aumento de suas intenções comunicativas(...) (Freire \& Parizzi, 2015).

Segundo Louro (2006), algumas habilidades que podem ser desenvolvidas com a musicoterapia são: o desenvolvimento e o aprimoramento da linguagem, a coordenação motora, a expressão corporal, além de processos cognitivos complexos, desenvolvimento da criatividade e aumento da capacidade de memorização do indivíduo. A autora explica que: "A música usa todas as regiões do cérebro e consegue remodela-lo". Segundo ela, indivíduos com TEA podem apresentar um processamento sensorial diferenciado, podendo processar melhor informações espaciais e concretas.

Pesquisas dentro do campo da Musicoterapia apontam que os indivíduos com Transtorno do aspecto autista tendem a manifestar uma capacidade intacta para percepção de melodias simples e um desempenho superior para processar elementos locais melódicos (Heaton, 2009).

Heaton (2009), enfatiza que existem casos que o autista não consegue se adaptar a determinados tipos de sons, o que pode lhes deixar ainda mais agitados, por isso a importância de conhecer e escolher com precisão como trabalhar com essa ferramenta. Nesse sentido, a escola precisa se relacionar com a realidade do aluno, aproximando-se e estabelecendo uma relação de confiança e afetividade no contexto da aprendizagem.

\section{Considerações Finais}

Com a realização desse estudo, pode-se concluir que o ensino de arte nos campos da música, teatro e dança tem alcançado bons resultados, possibilitando a inclusão não somente de alunos diagnosticados com autismo, mas também com outras necessidades educacionais. Estudos realizados por Fernandes et al., (2011), Louro (2006), Heaton (2009), Boato (2013) constataram que a arte contribui com o desenvolvimento afetivo, criativo e psicomotor de alunos com TEA, propiciando descobertas que vão além da comunicação verbal ou não-verbal, promovendo o estímulo à autoestima e à socialização desse

\footnotetext{
iii Os estudos encontrados nas bases não nos apresentam dados, por não se tratar de estudos quantitativos, mas sim percepções de desenvolvimento dos indivíduos envolvidos.
} 
alunato

Todavia, o alcance dos bons resultados demanda que o professor planeje suas ações considerando as peculiaridades de cada aluno, o que requer desse profissional paciência, atenção, cuidado e diálogo, visando garantir melhor qualidade de vida e de aprendizado aos alunos com autismo.

Futuramente é necessário um novo levantamento com o intuito de complementação do presente estudo, pois ele não verificou se o emprego da arte, na sua vertente visual (desenho e pintura), pode, de alguma forma contribuir com o desenvolvimento de pessoas com o transtorno do espectro autista.

\section{Referências}

Abreu, M., \& Cordiolli, M. (2011). Projeto de Lei do Plano Nacional de Educação (PNE 2011/2020): projeto em tramitação no Congresso Nacional / PL nº 8.035 / Brasília: Câmara dos Deputados, Edições Câmara, 106 p. - (Série ação parlamentar; n. 436).

Aleixo, G., \& Ruiz, M. C. (2008). A dança como forma de inserção social aos portadores da Síndrome do Autismo Asperger: relato de caso. (Monografia) Centro Universitário Católico Salesiano Auxilium (Unisalesiano), Lins-SP.

Araujo, k. K. (2015). A contribuição da música para o desenvolvimento e aprendizagem da criança Brasil Escola. Fonte: https://monografias.brasilescola.uol.com.br/pedagogia/a-contribuicao-da-musica-para-desenvolvimento-e-aprendizagem-da-crianca.htm\#indice_.

Arcoverde, S. (2008). A importância do teatro na formação da criança. In Anais do VIII Congresso Nacional de Educação (pp.600-609). Curitiba.

American psychiatric association APA (2013). Diagnostic and Statistical Manual of Mental Disorders. DSM-V, (5th ed.) Arlington, VA.

Associação americana de psiquiatria, APA (2014) V - Manual diagnóstico e estatístico de transtornos mentais. (5 ed.). Revista Artmed - Porto Alegre.

Boato, E. M. (2013). Metodologia de abordagem corporal para autistas.Tese de mestrado não-publicada, Programa de Pós-Graduação em Educação Física, Universidade Católica de Brasília, Brasília. https://bdtd.ucb.br:8443/jspui/handle/123456789/985.

Boato, E. M., Sampaio, T. M. V., Campos, M. C., Diniz, S. V., \& Albuquerque A. P. (2014). Expressão Corporal/Dança para Autistas-Um Estudo de Caso. Revista Pensar a Prática, 17(1). https://doi.org/10.5216/rpp.v17i1.17904.

Brasil - Decreto-lei $n^{\circ} 3.956$, de 8 de outubro de 2001 (2001). Promulga a convenção interamericana para a eliminação de todas as formas de discriminação contra as pessoas portadoras de deficiência. http://www.planalto.gov.br/ccivil_03/decreto/2001/d3956.htm. Brasília DF.

Brasil - Lei Federal $N^{o}$ 10.172, de 09 de janeiro de 2001 (2001). Aprova o plano nacional de educação e dá outras providências. http://www.planalto.gov.br/ccivil_03/leis/leis_2001/110172.htm. Brasília DF.

Brasil (2002). Estratégias a e orientações arte necessidades especiais. Brasília DF.

Brasil - Decreto-lei $n^{\circ}$ 6.094, de 24 de abril de 2007 (2007). Dispõe sobre a implementação do plano de metas compromisso todos pela educação, pela união federal, em regime de colaboração com municípios, distrito federal e estados, e a participação das famílias e da comunidade, mediante programas e ações de assistência técnica e financeira, visando a mobilização social pela melhoria da qualidade da educação básica. http://www.planalto.gov.br/ccivil_03/decreto/2001/d3956.htm. Brasília DF.

Brasil - Lei Federal No 12.764, de 27 de dezembro de 2012 (2012). regulamento institui a política nacional de proteção dos direitos da pessoa com transtorno do espectro autista; e altera o $\$ 3^{\circ}$ do art. 98 da Lei $n^{o}$ 8.112, de 11 de dezembro de 1990. http://www.planalto.gov.br/ccivil_03/_ato2011-2014/2012/lei/112764.htm. Brasília DF.

Brito, T. A. (2003). Música na educação infantil, propostas para a formação integral de crianças. São Paulo SP.

Castro, E. D., \& Lima, E. M. F. A. (2007). Resistência, inovação e clínica no pensar e no agir de Nise da Silveira. Interface Botucatu, vol.11 https://doi.org/10.1590/S1414-32832007000200017.

Carvalho, B. M., Evaristo, A. L. A., Octavio, A. J. M., \& Fantacini, Renata A. F. (2019). A inclusão do aluno com transtorno do espectro autista na educação infantil. Research, Society and Development, 8(1), Universidade Federal de Itajubá 2019

Conferência mundial de educação especial. A declaração de Salamanca. Sobre princípios, política e prática em educação especial. Salamanca, Espanha, 7 a 10 de Junho/1994. http://portal.mec.gov.br/seesp/arquivos/pdf/salamanca.pdf.

Dias, P. N., Oliveira, M. K. S. D., \& Farias, C. G. (2020). A arte-educação e libertação humana. Research, Society and Development. 9(11).

Fernandes, L. B., \& Schlesener, A. (2011). Ensino de arte no universo autista e o pensamento de Walter Benjamin na relação entre educação e arte. Revista Científica/FAP, http://periodicos.unespar.edu.br/index.php/revistacientifica/article/view/1539.

Forestier, R. (2011). Tudo sobre a Arte-Terapia: As bases científicas de uma profissão: A originalidade de uma prática terapêutica: seu estatuto profissional. ( $5^{\text {a }}$ ed.). Editora Ideias e Letras, São Paulo SP.

Freire, M., \& Parizzi, B (2015). As relações dos efeitos terapêuticos da Musicoterapia Improvisacional e o desenvolvimento musical de crianças com autismo. Revista Nupeart, 14, 46-55. 
Garcia, D. I. B., Jacomin, J. G., Dambros, A. R. T., \& Favaro, N. D. A. L. G. (2020). A estruturação do trabalho escolar ao aluno autista na escola de modalidade de educação especial: um estudo de caso no Norte do Paraná. Research, Society and Development, 9(10). Universidade Estadual do Paraná.

Gfeller, K. (2008). "Music: a HumanPhenomenon and Therapeutic Tool”. In: DAVIS, W.; GFELLER, K.; THAUT, M. AnIntroductionto Music Therapy: Theory and Practice. ( $3^{\mathrm{a}}$ ed.). Silver Spring: American Music TherapyAssociation.

Gómez, A. M. S., \& Terán, N. E. (2014). Transtornos de aprendizagem e autismo. (1ª ed.). 575p. Editora: Grupo Cultural, Maringá PR.

Heaton, P. Assessing musical skills in autistic children who are not savants. Phil. Trans. R. Soc. B. 2009; 364: 1443-1447.Heaton P et al. Can children with autistic

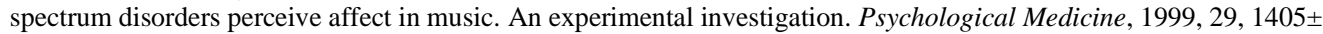

IDEB - Índice de desenvolvimento da educação básica (2019). <http://ideb.inep.gov.br/Site/.

Louro, V. D. S. (2006). Educação musical e deficiência: propostas pedagógicas. Viviane dos Santos Louro, Luís Garcia Alonso, Alex Ferreira de Andrade. Ed. do Autor. São José dos Campos, SP:

Machado, L. T. (2015). Dançaterapia no autismo: um estudo de caso. Fisioter. (22(2), 205-211). https://doi.org/10.590/1809-2950/11137322022015.

Maciel, L. C. T. (2019). A arte Visual como recurso metodologico na educação de crianãs com transtorno do espectro autismo. Trabalho de conclusão de curso - Universidade Estadual da Paraíba - Centro de Educação. Paraíba PB.

Mantoan, M. T. E. (2003) - Inclusão escolar: o que é? Por quê? Como fazer. Moderna - Coleção cotidiano escolar. São Paulo SP.

Mazzotta, M. J. S (1999). Educação Especial no Brasil: História e Políticas Públicas. Cortez. São Paulo SP.

Ministério da Educação - Secretaria de Educação Especial (2008). Experiências educacionais inclusivas II: Programa Educação Inclusiva: direito à diversidade. Brasília DF.

Ministério da Educação - Secretaria de Educação Especial (2010). Marcos político - legais da educação especial na perspectiva da educação inclusiva / secretaria de educação especial. Brasília DF.

Tommasi, S. B.,, \& Soares, L. F. M. (2015). O herói nos mitos gregos: arteterapia e educação. Editora Wak. Rio de Janeiro RJ.

Oliveira, K. G., \& Sertié, A. L. (2017). Griesi-Oliveira, K., \& Sertié, A. L. (2017). Transtornos do espectro autista: um guia atualizado para aconselhamento genético. Einstein (São Paulo), 15(2), 233-238. https://doi.org/10.1590/S1679-45082017RB4020.

Perola, C. E. (2018). Um Autista no teatro: reflexões autobiográficas e celebração da (neuro)diversidade. Trabalho de Conclusão de Curso - Universidade Federal de Pelota. Rio Grande do Sul RS.

Sampaio, L. M. T., \& Magalhaes, C. J. S (2017). Inclusão de Crianças com Autismo na Escola: Desafios do Professor. Anais da II Jornada Ibero-Americana de Pesquisa em Políticas Educacionais e Experiências Interdisciplinares na Educação, (Vol. 2), Curitiba PR.

Teixeira, M. L. (2015). Dança terapia no autismo: um estudo de caso. Fisioterapia e Pesquisa, 22(2), 205-211. https://dx.doi.org/10.590/1809-2950/11137322022015.

Vargas, S (2005). Diferentes linguagens na educação física: projeto Hip Hop na escola. Relato de experiência. Revista Digital Bueno Aires. http:// efdeportes.com/efd90/hiphop.htm.

Vygotski, L. $\quad$ S. $\quad$ (1999). Psicologia $\quad$ da $\quad$ arte. $\quad$ (Trad. $\quad$ Paulo $\quad$ Bezerra). fontes.

World federation of music therapy (2011). Whatis Music Therapy. http://www.wfmt.info/wfmt-new-home/about-wfmt/.

Yoshijinna, M. M. (2000). Autismo: orientação para os pais. Casa do Autista - Ministério da Saúde. Brasília DF. 